\title{
Features and Principles the Spread of Local Anesthetic Blockade of the Sciatic Nerve at Depends on the Amount of Anesthetic
}

\author{
Piacherski Valery, Marachkou Aliaksei
}

Health Care Institution, Mogilev Regional Hospital, Mogilev, The Republic of Belarus.

Email: pechersky.v@yandex.ru

Received November $27^{\text {th }}, 2013$; revised December $29^{\text {th }}$, 2013; accepted January $14^{\text {th }}, 2014$

Copyright (c) 2014 Piacherski Valery, Marachkou Aliaksei. This is an open access article distributed under the Creative Commons Attribution License, which permits unrestricted use, distribution, and reproduction in any medium, provided the original work is properly cited. In accordance of the Creative Commons Attribution License all Copyrights (C) 2014 are reserved for SCIRP and the owner of the intellectual property Piacherski Valery, Marachkou Aliaksei. All Copyright (c) 2014 are guarded by law and by SCIRP as a guardian.

\begin{abstract}
Aim: To study the features of local anesthetic solution spreading during sciatic nerve block in dependence on the anesthetic solution volume. Material and Methods: One hundred and sixty nine cases of sciatic nerve blocks done under ultrasonic visualization control were analyzed. Sciatic nerve blocks were performed by lidocaine in volumes $30 ; 25 ; 20 ; 15 ; 12.5 ; 10 ; 7.5 ; 6.5 ; 5 ; 4.5 \mathrm{ml}$. The cross-section area, equal to local anesthetic spreading, was determined; the extension of the anesthetic solution spreading along sciatic nerve was calculated. Results: The anesthetic agent solution spreads along sciatic nerve in proximal and distal direction, forming a kind of cylinder. The minimum volume of the local anesthetic, which covers sciatic nerve in the whole, is $5 \mathrm{ml}$. A rare (1.77\%) variation of sciatic nerve structure was described, in which tibial and common peroneal nerves develop directly from the branches of sacral plexus. Conclusion: The decrease of the local anesthetic volume leads to reduction of its spreading distance and cross-section area. Ultrasonic visualization can provide for sciatic nerve anatomical peculiarities, which can have an effect on the block quality.
\end{abstract}

\section{KEYWORDS}

Sciatic Nerve Block; Ultrasound-Guided; Local Anesthetic Spreading

\section{Introduction}

The block of sciatic nerve is performed more than hundred years by different manners. For verifying the position of injection needle about sciatic nerve, the methods of paresthesia search and electric stimulation of peripheral nerves were applied [1]. Use of ultrasound-guided regional anesthesia increases efficiency up to $96 \%$ - $100 \%$ [2-4]. With the development of new technologies, new methods of verifying the position of injection needle about a nerve appeared which can evaluate the characteristics of local anesthetic spreading in such kind of peripheral blocks, as stellate ganglion block [5]. There are conflicting data on the minimum effective volume and quantity of local anesthetics used for the blockade of the sciatic nerve [6-8]. In our opinion, the study of features and nature of the spread of local anesthetic blockade in the sciatic nerve will most accurately examine the use of low doses of local anesthetics.

Aim of the work. To study the features of local anesthetic solution spreading during sciatic nerve block in dependence on the injected anesthetic solution volume.

\section{Material and Methods}

We have analyzed the results of 169 cases of sciatic nerve block in combination with femoral nerve block, in 169 patients. The age of patients was $42.3 \pm 13.7$ years. Sexes distribution was: 104 male and 65 female patients. All patients had an operation on the occasion of posttraumatic damage and disfunction of lower extremities, removal of the metal constructions after bones osteosyn- 
thesis in lower extremities. The criterion of exclusion from the research was anomalous sciatic nerve anatomy. Such clinical cases are described separately in an appropriate section of the article.

The criteria of inclusion patients in research were: destination to operation, requiring anesthesia; presence of written informed consent of the patient about the kind of anesthesia and its probable complications. The criteria of exclusion were: patient's denial of the proposed kind of anesthesia; age $<18$, weight $<50$, physical status value according to ASA $>3$, allergic reactions on the applied medications in anamnesis, coagulopathy, infectious skin lesions in area of injection, neurological or nerve-muscular diseases, heavy liver diseases or kidney deficiency, impossibility of cooperation with patient.

For providing the intraoperational anesthesia, all blocks were performed by lidocaine solution of different concentrations, of the volume $40 ; 30 ; 25 ; 20 ; 15 ; 12.5 ; 10$; $7.5 ; 6.5 ; 5 ; 4.5 \mathrm{ml}$, with addition of adrenalin (1:200 000). All patients with the aim of premedication administered orally diphenhydramine $50 \mathrm{mg}$ before the day of operation (22.00) and at morning (7.00) at the day of operation. Atropine 0.5 - $0.8 \mathrm{mg}$ and dimedrol $10 \mathrm{mg}$ were injected intramuscularly 20 - 30 min before the block performing. With the aim of sedation, sibazon $10 \mathrm{mg}$, fentanyl $0.1 \mathrm{mg}$ and (or) propofol 40 - $60 \mathrm{mg}$, were injected intravenously in operating-room before the block.

Sciatic nerve block was performed by a subgluteal approach $[9,10]$. For verifying the position of the needle and sciatic nerve, ultrasonic visualization in combination with peripheral nerves electric stimulator were applied. In this procedure, after obtaining the sonographic signs of sciatic nerve at ultrasonic apparatus screen, the injection needle was approached to the nerve under ultrasonic control, till the appearance of muscle contractions of the appropriate muscle group. The frequency of nerve stimulation was $1-2 \mathrm{~Hz}$; the electric stimulator generated impulses of direct current with the strength $0.1-1.0 \mathrm{~mA}$, voltage $1-10 \mathrm{~V}$ and impulse length $0.1 \mathrm{msec}$.

The ultrasonic research apparatus Aloka SSC 400, supplied with line sensors with frequency 3.5 and 7.5 $\mathrm{MHz}$, was used for ultrasonic visualization of nerve stems. Ultrasonic scanning enabled to control completely the spreading of local anesthetic around and along the nerve. After the muscular response and aspiration probe execution, a solution of local anesthetic was injected into the fascial sheath of the sciatic nerve ("fascial plane concept”) [8].

All patients were distributed to 11 groups in dependence of the applied volume of lidocaine solution, having different concentrations. Sciatic nerve blocks by $40 \mathrm{ml}$ of solution were performed in 58 patients; $30 \mathrm{ml}$ of the local anesthetic were applied in 29 individuals; 25 ml-in 16 individuals; $20 \mathrm{ml}-$ in 9 individuals; $15 \mathrm{ml}-$ in 12 individuals; $12.5 \mathrm{ml}$-in 6 individuals (1\% lidocaine solution); $10 \mathrm{ml}$-in 12 individuals; $7.5 \mathrm{ml}$-in 5 individuals; 6.5 ml-in 5 individuals; 5 ml-in 9 individuals; 4.5 ml-in 5 individuals. If the local anesthetic solution volume was less than $12.5 \mathrm{ml}$, the solution concentration was $2 \%$; if the volume was $7.5 \mathrm{ml}$ and less, the solution concentration was $3 \%$ and $4 \%$, which enabled to reach a sufficient level of intraoperational anesthesia and did not provoke patient's discomfort. Anesthesia complications in intraoperational and post-operational period were not noted.

After the block performing, the second anesthesiologist, who did not know about the amount of injected local anesthetic solution, independently measured cross-section area of sciatic nerve $\left(\mathrm{S}_{1}\right)$ and total cross-section area of sciatic nerve together with the ring of local anesthetic around the nerve $\left(\mathrm{S}_{2}\right)$. These measurements were done by means of ultrasonic apparatus software. The cross-section area of the ring (S), corresponding to local anesthetic, was defined as the difference between $S_{2}$ and $S_{1}$. The measurements were repeated three times, and the dispersion between averages did not exceed 15\%.

As our ultrasonic research showed, the local anesthetic spread in all directions around the nerve, forming an irregular cylinder (Figure 1). Taking into account such character of spreading, to determine the length of anesthetic passing along the nerve, we applied the formula

$$
L=\frac{V}{S}
$$

where $L$-the length of local anesthetic spreading $(\mathrm{cm})$, $V$-the volume of injected local anesthetic (ml), $S$-cross-section area of local anesthetic $\left(\mathrm{cm}^{2}\right)$. Some reduction in cross-section area of local anesthetic was
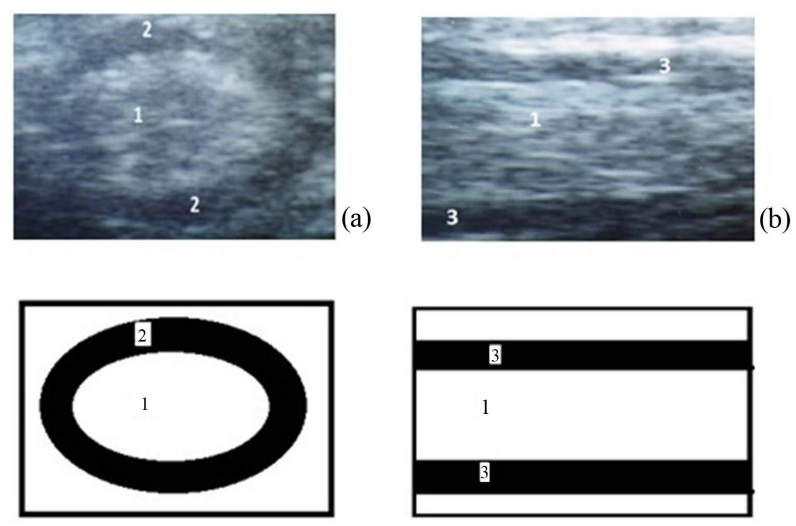

Figure 1. Ultrasonic visualization of sciatic nerve after performing the block by $40 \mathrm{ml} 1 \%$ lidocaine in patient $\mathrm{C}$ (a) cross-section; b) longitudinal section), where 1-sciatic nerve, 2-“ring” of local anesthetic, 3-spreading of the local anesthetic proximally and distally from the point of injection. Comment: under each picture there is the scheme, explaining the ultrasonic image. 
noted towards the proximal and distal ends of its spreading. Taking into account this circumstance, we carried out the control measuring of the local anesthetic spreading length. It was done by means of ultrasonic examination and based on sonographic sings of the presence or absence of anesthetic solution around sciatic nerve. The data obtained differed $\pm 0.7 \mathrm{~cm}$ from the calculated values.

Statistical processing was carried out by Statistica 7.0 software. Data are presented as mean and standard deviation. Statistical significance of the differences between averages was estimated by means of nonparametrical dispersion analysis (Kruskal-Wallis ANOVA). We accepted the reliable differences between groups if $p<0.05$. The method of nonparametrical correlation analysis Kendall tau was applied for studying the connection between two characteristics in groups.

The research was carried out after the permission given by Ethics Committee at Health Care Institution "Mogilev Regional Hospital”, protocol No.3/C dated 2 Aug 2010.

\section{Results and Discussion}

The data about local anesthetic extension length (L) and cross-section area (S) are shown in Table 1. The change in cross-section area (S) in dependence of local anesthetic volume is demonstrated at Figure 2. As seen, crosssection area of the local anesthetic decreases along with its volume. It was stated, that no complete wrapping round sciatic nerve is observed, if $4.5 \mathrm{ml}$ of the solution are applied.

As seen from Figure 3, the decrease in calculated length of local anesthetic solution spreading along sciatic nerve occurs along with the decrease of the applied volume of the solution. Kendall tau correlation coefficient for the values (illustrated at Figure 2) is 0.77 ( $p<0.001$ ), which is the evidence of the high correlation level be-

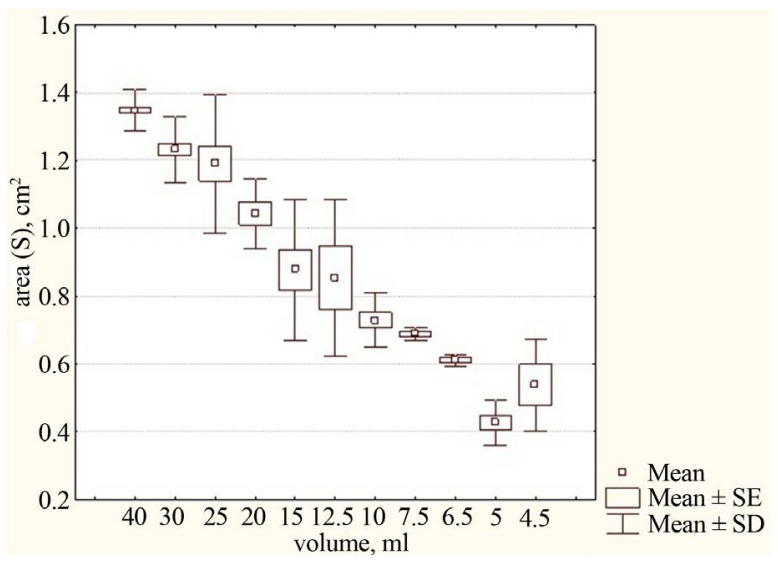

Figure 2. Change in cross-section area of the local anesthetic (S) in dependence of its volume.

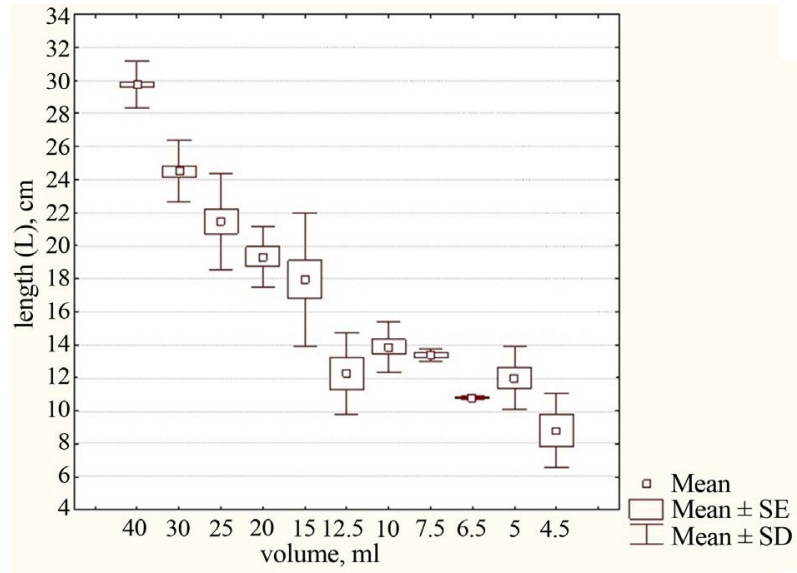

Figure 3. Change in the length of local anesthetic spreading (L) along sciatic nerve in dependence of the anesthetic volume.

Table 1. Values of local anesthetic extension length (L) and cross-section area $(\mathrm{S})$.

\begin{tabular}{ccc}
\hline $\mathrm{V}, \mathrm{ml}$ & $\mathrm{L}, \mathrm{cm}$ & $\mathrm{S}, \mathrm{cm}^{2}$ \\
\hline $40(\mathrm{n}=58)$ & $29.0 \pm 1.3$ & $1.34 \pm 0.06$ \\
$30(\mathrm{n}=29)$ & $24.4 \pm 1.8$ & $1.2 \pm 0.09$ \\
$25(\mathrm{n}=16)$ & $21.4 \pm 1.8$ & $1.19 \pm 0.19$ \\
$20(\mathrm{n}=9)$ & $19.3+1.7$ & $1.04 \pm 0.09$ \\
$15(\mathrm{n}=12)$ & $17.9 \pm 4.0$ & $0.87 \pm 0.2$ \\
$12.5(\mathrm{n}=6)$ & $12.2 \pm 2.4$ & $0.85 \pm 0.2$ \\
$10(\mathrm{n}=12)$ & $13.8 \pm 1.5$ & $0.95 \pm 0.3$ \\
$7.5(\mathrm{n}=5)$ & $13.3 \pm 0.34$ & $0.68 \pm 0.01$ \\
$6.5(\mathrm{n}=5)$ & $10.8 \pm 0.09$ & $0.61 \pm 0.01$ \\
$5(\mathrm{n}=9)$ & $11.9 \pm 1.7$ & $0.42 \pm 0.67$ \\
$4.5(\mathrm{n}=5)$ & $8.7 \pm 1.9$ & $0.53 \pm 0.13$ \\
\hline
\end{tabular}

tween these characteristics.

Thus, it was stated, that local anesthetic solution during sciatic nerve block by subbuttock admission spreads in proximal and distal directions, forming a kind of cylinder, which wraps round the nerve. The minimum volume of the local anesthetic, wrapping totally round the nerve, is $5 \mathrm{ml}$. The increase of local anesthetic volume leads to the increase both of cross-section area of the anesthetic spreading and length of its extension along sciatic nerve. We make the conclusion that the structure of sciatic nerve fascial sheath enables to local anesthetic spreads with uniform increase of both cross-section area and length of extension, if the solution volume is increased.

The data described above were obtained for the clas- 
sical variant of sciatic nerve anatomy, viz. if its subdivision into tibial and common peroneal nerves begins in the region of popliteal pit. During the study of local anesthetic spreading in 169 patients, anomalous structure of sciatic nerve was noted in $3(1.77 \%)$ patients. Anatomical peculiarities of sciatic nerve can sufficiently effects the local anesthetic spreading around the nerve. A variant of sciatic nerve anatomy is its early division into tibial and common peroneal nerve at the level of subbuttock fold. In some instances there is the absence of sciatic nerve as a single anatomical structure. In this case tibial and common peroneal nerves develop from branches of sacral plexus. Ultrasonic image of sciatic nerve with anomalous structure, after performing its block by subbuttock admission, is shown at Figure 4.

As seen from the scanogram, the anesthetic agent spread around the two nerves: tibial and common peroneal. The following peculiarities were noted during the block performing: two nerves were being visualized in subbuttock region; during common peroneal nerve block the local anesthetic did not spread around tibial nerve, and this demanded an additional block, i.e. injection of local anesthetic to tibial nerve. The spread of local anesthetic in proximal direction and around two nerves was observed during the subsequent ultrasonic control.

Thus, in the considered clinical case, we met with a rare variant of sciatic nerve anatomy. The analysis of anesthetic spreading around two nerves showed, that in the lack of ultrasonic guidance, in such the case we can get an ineffective block of sciatic nerve.

The disadvantage of this study is the inability to complete blindness. Just to simplify the calculations we took the cross sectional area of the sciatic nerve at a constant value. A small number of patients in some groups was due to the lack of adequate anesthesia, when applying these volumes anesthetic (in accordance with the opinion of the ethics committee).

From the analysis of the data shows that the introduction of $4.5 \mathrm{~mL}$ of local anesthetic agent is distributed along the sciatic nerve in its fascial compartment, without extending around the entire circumference of the sciatic nerve. When administered $5 \mathrm{ml}$ complete solution

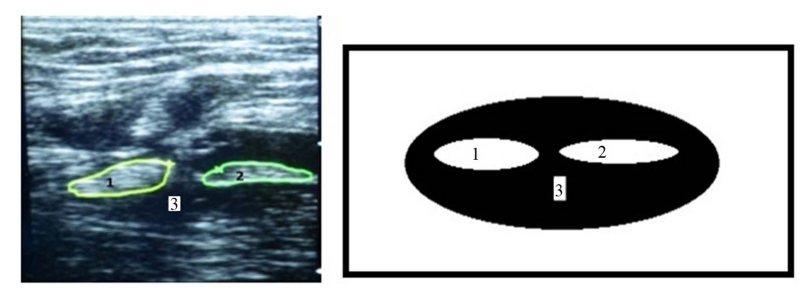

Figure 4. Ultrasonic image and scheme of local anesthetic spreading in the case of anomalous anatomical structure of sciatic nerve (left lower extremity): 1-common peroneal nerve, 2-tibial nerve, 3 -local anesthetic. occurs "enveloping" sciatic nerve, while there is a significant increase in the length of the propagation of local anesthetic along the sciatic nerve. The cross sectional area changes significantly, due to the spread of the solution around the entire circumference of the sciatic nerve. Further, if the volume of the local anesthetic solution was $6.5 \mathrm{ml}$ to a significant increase in cross-sectional area of the local anesthetic without changing its length in relation to the propagation length distribution in the group of $10(5 \mathrm{~mL})$. Thus, at this stage, the local anesthetic does not spread along the sciatic nerve and in the transverse direction of the sciatic nerve, as if by stretching nerve fascial sheath circumferentially.

Further there is a distribution of local anesthetic along the sciatic nerve in the form of a cylinder in the proximal and distal direction. In the distal and proximal ends of the directions is narrowed "cylinder" of local anesthetic solution.

Minimum volume of local anesthetic solution, which wraps totally around sciatic nerve in adult patients, is 5 $\mathrm{ml}$. The full spreading of the local anesthetic around sciatic nerve was not observed, if $4.5 \mathrm{ml}$ of the solution were used. The decrease of local anesthetic volume leads to decrease in solution extension length and its crosssection area.

Earlier Latzke et al. study was conducted in which was shown dependence of the effective blockade of the sciatic nerve on the ratio of the area of the sciatic nerve and local anesthetic [7]. In our opinion, further studies of this problem with combining techniques proposed Latzke et al. and in our work will help identify patterns when searching for low doses of local anesthetics not only the blockade of the sciatic nerve, and other peripheral nerves.

\section{Conclusion}

Ultrasonic visualization during sciatic nerve block can reveal the nerve anatomical peculiarities, and thus promote the effectiveness of anesthesiological aid.

\section{REFERENCES}

[1] M. Malroj, "Regional Anaesthesia: Illustrated Practice Book,” 3rd Edition. Wolters Kluwer/Lippincott Williams \& Wilkins, Philadelphia, 2002, p. 333.

[2] Q. H. De Tran, P. Bertini, C. Zaouter, L. Muñoz and R. J. Finlayson, “A Prospective, Randomized Comparison between Single- and Double-Injection Ultrasound-Guided Infraclavicular Brachial Plexus Block,” Regional Anesthesia \& Pain Medicine, Vol. 35, No. 1, 2010, pp. 16-21.

[3] P. Marhofer, M. Greher and S. Kapral, "Ultrasound guidance in regional anaesthesia," British Journal of Anaesthesia, Vol. 94, No. 1, 2005, pp. 7-17.

http://dx.doi.org/10.1093/bja/aei002

[4] V. Piacherski, A. Marochkov, A. Brukhnou and Z. Kok- 
han, "Comparison of Three Methods of Regional Anesthesia of Peripheral Nerves and Plexuses," Open Journal of Anesthesiology, Vol. 2, No. 5, 2012, pp. 237-243. http://dx.doi.org/10.4236/ojanes.2012.25056

[5] M. K. Son, R. K. Chung, Y. J. Kim, D. Y. Kim, H. S. Lee and J. I. Han, "The Effects of Local Anesthetic Distribution on Symptoms Using Ultrasound Image after Stellate Ganglion Block,” Korean Journal of Anesthesiology, Vol. 57, No. 5, 2009, pp. 579-583. http://dx.doi.org/10.4097/kjae.2009.57.5.579

[6] P. Marhofer, W. Harrop-Griffiths, S. C. Kettner and L. Kirchmair, "Fifteen Years of Ultrasound Guidance in Regional Anaesthesia: Part 1,” British Journal of Anaesthesia, Vol. 104, No. 5, 2010, pp. 538-546. http://dx.doi.org/10.1093/bja/aeq069

[7] D. Latzke, P. Marhofer, M. Zeitlinger, A. Machata, F. Neumann, E. Lackner, et al., "Minimal local anaesthetic volumes for sciatic nerve block: evaluation of ED99 in volunteers,” British Journal of Anaesthesia, Vol. 104, No., 2010, pp. 239-244.

[8] V. Piacherski and A. Marochkov, "A Comparison of the
Onset Time of Complete Blockade of the Sciatic Nerve in the Application of Ropivacaine and Its Equal Volumes Mixture with Li-Docaine: A Double-Blind Randomized Study," Korean Journal of Anesthesiology, Vol. 65, No. 1, 2013, pp. 42-47. http://dx.doi.org/10.4097/kjae.2013.65.1.42

[9] J. E. Chelly, "Peripherial Nerve Blocks: A Color Atlas," 3rd Edition, Wolters Kluwer/Lippincott Williams \& Wilkins, Philadelphia, 2009, pp. 1-474.

[10] G.-J. van Geffen, “The Value of Ultrasonography for Performing Peripheral Nerve Blocks. Theory, Practice and Clinical Experience in Adults and Children,” Optima Grafische Communicatie, Rotterdam, 2008. pp. 234-279.

[11] H. L. Andersen, S. L. Andersen and J. Tranum-Jensen, "Injection inside the Paraneural Sheath of the Sciatic Nerve: Direct Comparison among Ultrasound Imaging, Macroscopic Anatomy, and Histologic Analysis,” Regional Anesthesia and Pain Medicine, Vol. 37, No. 4, 2012, pp. 410-414.

http://dx.doi.org/10.1097/AAP.0b013e31825145f3 